\title{
Contribution of pre-varicocelectomy color Doppler ultrasonography finding to surgery and its correlation with semen parameters
}

\author{
Caner Ediz ${ }^{1}$, Muhammed Cihan Temel ${ }^{1}$, Suna Şahin Ediz ${ }^{2}$, Serkan Akan ${ }^{1}$, Serkan Yenigürbüz ${ }^{1}$, \\ Mehmet Pehlivanoğlu ${ }^{1}$, Ömer Yılmaz ${ }^{1}$ \\ ${ }^{1}$ Department of Urology, Sultan Abdulhamid Han Education and Research Hospital, Istanbul, Turkey; \\ ${ }^{2}$ Department of Radiology, Kartal Dr. Lutfi Kirdar City Hospital, Istanbul, Turkey.
}

\begin{abstract}
Summary Background: This study aimed to determine the contribution of color Doppler ultrasonography (CDUS) performed before varicocelectomy to the success of surgical treatment and to evaluate the correlation between CDUS findings and semen parameters.

Methods: A total of 84 patients diagnosed with grade 3 left varicocele in our clinic between 2016 and 2018 were evaluated. The patients in whom the decision for varicocelectomy was based on only physical examination (PE) findings and abnormal semen analysis (SA) were defined as Group 1, while the patients undergoing varicocelectomy based on PE, CDUS and SA findings were defined as Group 2. The patients diagnosed with varicocele based on PE and CDUS findings who were included in a followup protocol due to normal semen parameters were defined as Group 3.

Results: In Group 1, there was a total of 28 patients and the mean number of ligated internal spermatic veins was 4.53 (range, 2-10). In Group 2, there was a total of 30 patients and the number of ligated internal spermatic veins was 3.76 (range, 1-8). No statistically significant difference was found between Group 1 and 2 in terms of the number of internal spermatic veins ligated during varicocelectomy. No statistically significant correlation was found between semen parameters and the number of veins ligated during varicocelectomy in Group 1 and 2 and between semen parameters and CDUS findings group 2 and 3. Conclusions: In patients with primary grade 3 varicocele, diagnosed by physical examination there is no need for additional imaging in primary cases.
\end{abstract}

KEY WORDS: Varicocele; Varicocelectomy; Color Doppler ultrasonography; Semen parameters;

Number of vein ligated.

Submitted 25 December 2020; Accepted 3 February 2021

\section{INTRODUCTION}

Varicocele is defined as the dilatation of the veins of the pampiniform plexus. Diagnostic methods, including physical examination, Doppler stethoscope examination, thermography, color Doppler ultrasonography (CDUS), scintigraphy, and venography are used for the diagnosis of varicocele, although the current view is that physical examination is sufficient and additional imaging methods are not always required for the diagnosis of varicocele.
After the physical exam, varicocele can be confirmed by CDUS (1) and CDUS may be required in the presence of factors interfering with physical examination.

The aim of the current treatment is the ligation of internal and external spermatic vein branches while preserving all arterial structures, lymphatics and the vas deferens. In general, varicocelectomy is performed in patients with poor semen quality, providing improvement in semen parameters in $50-80 \%$ of the patients and, in addition, varicocele repair may result in improvements in natural pregnancy rates (2-6). There are studies on the optimal number of veins to be ligated, which varies upon the varicocelectomy technique, while there are not many studies on the parameters effectively predicting this number and on the correlation of surgical success with the number of ligated spermatic veins.

In our study, we aimed to evaluate the correlation of pre-varicocelectomy physical examination findings and of CDUS measurement results with the number of internal/external spermatic veins ligated during surgery and to analyze whether CDUS findings correlate with semen parameters.

\section{MATERIALS AND METHODS}

\section{Patient population}

A total of 84 patients diagnosed with grade 3 left varicocele in our clinic between November 15, 2016 and November 15, 2018 were evaluated. Patients over 18 years of age who had infertility or abnormal semen parameters or scrotal pain (resistant to medical treatment) with grade 3 left varicocele (visible and palpable spermatic veins without Valsalva maneuver at rest) were included in the study. Patients who were found to have missing data during data recording, evaluation or analysis, recurrent cases with a history of varicocelectomy, patients with endovascular treatment history for varicose veins and patients under 18 years were excluded from the study.

Study sesign

The study was designed as a retrospective study. No patients underwent any additional tests or assessments

No conflict of interest declared. 
other than the evaluations performed for the diagnosis of varicocele in routine urologic practice (physical examination, semen analysis and, if required, CDUS). All procedures performed in this study were in accordance with the ethical standards of the institutional research committee and with the 1964 Helsinki declaration and its later amendments or comparable ethical standards. All participating patients gave written informed consent.

In all patients, presence and localization of scrotal pain, presence of scrotal swelling, presence of infertility, varicocele grade, semen parameters (total sperm volume, total sperm count, sperm count per milliliter, ratio of forward moving sperms/motile sperms without progressive movement/immotile sperms, ratio of sperms with normal morphology, mean sperm velocity, ejaculate $\mathrm{pH}$, presence of pyospermia) and the number of internal/external spermatic veins ligated during varicocelectomy were recorded. Additionally, in accordance with the guideline recommendation, the width of the pampiniform venous plexus was evaluated with CDUS and the diameter of the varicose spermatic vein measured during the Valsalva maneuver was recorded in required patients. All semen analysis results were evaluated using the reference values defined by World Health Organization (WHO) in 2010. The time interval of two semen analysis for each patient was 15 days. The average of two semen analyzes for each patient was taken.

SonoScape S40 CDUS system (Australia) was used in all patients undergoing CDUS. A 7.5 Mhz-linear probe was used during measurements. First, the testicular structure was examined using grayscale ultrasonography during normal respiration by elevating the chest and head region by $15^{\circ}$ while the patients were in supine position. Testicular volume was measured by using the "prolate ellipse" formula (W x H x D x 0.52). Plexus pampiniformis veins were evaluated by identifying the most dilated vein and then measuring the increase in its diameter during the Valsalva maneuver.

The presence of reflux was assessed using the color mode during normal respiration and the Valsalva maneuver.

The patients in whom the decision for varicocelectomy was based on only physical examination (PE) findings and semen analysis (SA) were defined as Group 1, while the patients undergoing varicocelectomy based on PE, CDUS and SA findings were defined as Group 2.

The patients diagnosed with varicocele based on PE and CDUS findings who were included in the follow-up protocol due to normal semen parameters were defined as Group 3. Thus, it was planned to compare the contribution of CDUS to varicocelectomy (between Group 1 and 2 ) and its correlation in patients with normal or abnormal semen parameters (between Group 2 and 3). There were 28, 30 and 26 patients in Group 1, 2, and 3, respectively.

The patients in Group 1 and 2 underwent left subinguinal varicocelectomy (the routine procedure in our clinic) for the diagnosis of grade 3 left varicocele. The patients undergoing varicocelectomy had at least two sperm parameter lower than the SA reference values defined by WHO or infertility. Varicocelectomy was not performed in patients with only scrotal pain and normal SA results. Subinguinal varicocelectomy was performed under spinal or general anesthesia. The testis was not routinely delivered from the scrotum and the visible external spermatic vein(s) and internal spermatic veins were ligated by preserving testicular arterial and lymphatic vessels.

The patients in Group 3 were enrolled into follow-up to control the changes in semen parameters at 6-month intervals.

\section{Study aim}

The study had two primary objectives. Firstly, we aimed to evaluate the adequacy of physical examination by investigating whether there was a statistically significant difference between Group 1 and 2 in terms of the number of internal and external spermatic veins ligated during varicocelectomy and to assess the contribution of radiological imaging to the determination of the optimal number of spermatic veins to be ligated. In addition, we analyzed whether each of the recorded parameters of the patients were in correlation with the number of ligated external and internal spermatic veins. The second aim was to investigate the presence of a correlation between the maximum spermatic vein diameter measured using CDUS during the Valsalva maneuver and semen parameters in Group 2 and 3 patients. We thereby aimed to evaluate the correlation between semen parameters and additional radiological imaging findings in patients with Grade 3 varicocele.

\section{Statistical analysis}

Statistical analyses were performed using SPSS Statistics 22.0 software (SPSS Inc., Chicago, IL, USA). The normality hypothesis was tested using the Kolmogorov-Smirnov test during data analysis. Descriptive statistics for continuous variables were presented as median and minimum-maximum values. The independent-samples t-test and Mann-Whitney U-test were used to analyze data not conforming to a normal distribution. Pearson and Spearman tests were used for correlation analyses. Statistical significance was defined as $\mathrm{p}<0.05$.

\section{RESULTS}

The median ages of the patients were 27.5 years (range, 22-39 years) in Group 1, 24.5 years (range, 19-39 years) in Group 2 and 26 years (range, 18-35 years) in Group 3. Regarding primary presenting complaints, testicular pain and scrotal swelling were present in $39.28 \%$ (11/28) and 39.28\% (11/28) of the patients in Group 1, respectively; in $53.33 \%(16 / 30)$ and $30 \%(9 / 30)$ of the patients in Group 2, respectively; and in 69.23\% (18/26) and $30.77 \%(8 / 26)$ of the patients in Group 3, respectively. Infertility was the presenting complaint in $25 \%$ $(7 / 28)$ and $16.66 \%(5 / 30)$ of the patients in Group 1 and 2 , respectively.

In Group 1, there was a total of 28 patients and the total number of ligated internal spermatic veins was 127 . The median number of ligated internal spermatic veins was 4 (range, 2-10) in Group 1. In Group 2, there were a total of 30 patients and the total number of ligated internal spermatic veins was 113 . The median number of ligated internal spermatic veins was 4 (range, 1-8) in Group 2. 
Table 1.

No statistically significant difference was found between Group 1 and 2 in the number of internal and external spermatic veins ligated during varicocelectomy $(p>0.05)$

\begin{tabular}{|l|c|c|c|}
\hline & $\begin{array}{c}\text { Group } \mathbf{1}(\mathbf{n}=\mathbf{2 8}) \\
\text { Median }(\mathbf{m i n}-\max )\end{array}$ & $\begin{array}{c}\text { Group } \mathbf{2}(\mathbf{n}=\mathbf{3 0}) \\
\text { Median }(\mathbf{m i n}-\mathbf{m a x})\end{array}$ & $\mathbf{p}$ value \\
\hline Internal spermatic vein & $4(2-10)$ & $4(1-8)$ & 0.114 \\
\hline External spermatic vein & $0(0-2)$ & $0(0-2)$ & 0.845 \\
\hline
\end{tabular}

No statistically significant difference was found between Group 1 and 2 in the number of internal spermatic veins ligated during varicocelectomy $(p=0.114)$ (Table 1$)$. The total number of ligated external veins was 17 and the median number was 0 (range, 0-2) in Group 1. A total of 16 external spermatic veins were ligated and the median number of ligated external spermatic veins was 0 (range, 0-2) in Group 2. No statistically significant difference was found between Group 1 and 2 in terms of the number of external spermatic veins ligated during varicocelectomy $(p=0.845)$ (Table 1$)$.

A statistically significant positive correlation was found between the number of internal spermatic veins and the number of external spermatic veins ligated during varicocelectomy in Group 1 and 2 ( $\mathrm{p}=0.023$ and $\mathrm{p}=0.049$ ). However, a correlation analysis between the numbers of ligated internal and external spermatic veins and semen parameters found no statistically significant correlation in either groups ( $\mathrm{p}>0.05)$ ( $\mathrm{p}$ and $\mathrm{r}$ values) (Table 2). In Group 2, a correlation analysis was conducted to examine the correlation of the maximum spermatic vein diameter measured by CDUS during the Valsalva maneu- ver with semen parameters and the number of ligated external and internal spermatic veins. In conclusion, the maximum spermatic vein diameter measured during the Valsalva maneuver was not significantly correlated with any of the semen parameters or the numbers of ligated external and internal spermatic veins ( $p>0.05)$ ( $p$ and $\mathrm{r}$ values) (Table 3 ).

In Group 3, there was also no statistically significant correlation between semen parameters and the maximum spermatic vein diameter measured during the Valsalva maneuver $(\mathrm{p}>0.05)$.

\section{Discussion}

Varicocele is the most common correctable cause of male infertility (7). Approximately $19-41 \%$ of the patients presenting with primary infertility are diagnosed with varicocele $(8,9)$, while this rate ranges from $45 \%$ to $81 \%$ in patients presenting with secondary infertility (9). The most likely cause of impaired spermatogenesis is testicular hyperthermia associated with varicocele, while increased reactive oxygen products and apoptosis are closely related to the pathophysiology of varicocele (7). Varicocele is usually asymptomatic but testicular pain may be the first presenting symptom in $10 \%$ of the patients. It is usually unilateral. Surgical treatment is extremely successful and relieves pain in $90 \%$ of the patients in cases where chronic testicular pain etiologically determined to be caused by varicocele is not relieved by conservative treatment (10). CDUS may have a role in the possible differential diagnoses particularly in cases of unexplained scrotal pain. Raghavendran et al. (11) reported that severe testicular pain in a patient diag-

Table 2.

Correlation Analysis between semen parameter results and the numbers of ligated internal and external spermatic veins in Group 1 and 2. No positive correlation was found between any of the parameters evaluated in semen analysis and the number of ligated veins $(p>0.05)$.

\begin{tabular}{|c|c|c|c|c|c|c|}
\hline & \multicolumn{2}{|c|}{ Semen analysis results } & \multicolumn{4}{|c|}{$\begin{array}{l}\text { P-values for the correlation analysis between semen analysis } \\
\text { and the number of ligated internal and external spermatic veins in Group } 1 \text { and } 2\end{array}$} \\
\hline & $\begin{array}{l}\text { Group } 1(\mathrm{n}=\mathbf{2 8}) \\
\text { Median (min-max) }\end{array}$ & $\begin{array}{l}\text { Group } 2(n=30) \\
\text { Median (min-max) }\end{array}$ & $\begin{array}{c}\text { Group } 1 \\
\text { Internal spermatic vein }\end{array}$ & $\begin{array}{c}\text { Group } 1 \\
\text { External spermatic vein }\end{array}$ & $\begin{array}{c}\text { Group } 2 \\
\text { Internal spermatic vein }\end{array}$ & $\begin{array}{c}\text { Group } 2 \\
\text { External spermatic vein }\end{array}$ \\
\hline Semen volume (ml) & $2.3(1-5)$ & $3(1-5)$ & 0.59 & 0.08 & 0.25 & 0.54 \\
\hline Sperm count $\left(10^{6} / \mathrm{ml}\right)$ & $27.45(0-127)$ & $13.2(0-89.6)$ & 0.28 & 0.42 & 0.98 & 0.32 \\
\hline Total sperm count $\left(x 10^{6}\right)$ & $75(0-345)$ & $46(0-224)$ & 0.46 & 0.42 & 0.78 & 0.24 \\
\hline Forward moving (\%) & $23(0-75.4)$ & $23(0-60)$ & 0.23 & 0.78 & 0.85 & 0.31 \\
\hline Motile without progressive movement (\%) & $17.81(0-62.3)$ & $21.1(0-39)$ & 0.74 & 0.42 & 0.16 & 0.66 \\
\hline Immotile (\%) & $49.5(0-78)$ & $50(0-95)$ & 0.75 & 0.5 & 0.98 & 0.34 \\
\hline Morphology (\%) & $8(0-34)$ & $4(0-20)$ & 0.45 & 0.181 & 0.57 & 0.21 \\
\hline
\end{tabular}

Table 3.

Correlation analysis between semen parameters and spermatic vein diameters measured by CDUS in Group 2 and 3 . No positive correlation was found between any of the parameters evaluated in semen analysis and spermatic vein diameter $(p>0.05)$.

\begin{tabular}{|c|c|c|c|c|c|c|c|c|}
\hline & & \multicolumn{7}{|c|}{ P-values for the correlation analysis between semen analysis results and spermatic vein diameters measured by CDUS in Group 2 and 3} \\
\hline & $\begin{array}{l}\text { Spermatic vein diameter } \\
\text { measured by CDUS } \\
\text { Median (mm) (min-max) }\end{array}$ & Semen volume & Sperm count & $\begin{array}{c}\text { Total } \\
\text { sperm count }\end{array}$ & $\begin{array}{l}\text { Forward } \\
\text { moving }\end{array}$ & $\begin{array}{l}\text { Motile without } \\
\text { progressive } \\
\text { movement }\end{array}$ & Immotile & Morphology \\
\hline Group $2(n=30)$ & $3.8(2.8-7)$ & 0.99 & 0.96 & 0.78 & 0.57 & 0.055 & 0.98 & 0.37 \\
\hline Group $3(n=26)$ & $2.9(2.3-4)$ & 0.54 & 0.56 & 0.85 & 0.9 & 0.4 & 0.68 & 0.9 \\
\hline
\end{tabular}


nosed with varicocele was due to a thrombus in a varicose vein. Presenting complaints may include prominence of testicular vessels and feeling of unilateral scrotal swelling in addition to testicular pain. The dilatation of spermatic veins causes an increase in the temperature in the testicles and scrotum. This increase in temperature may cause a progressive dysfunction in the testicles and epididymis, leading to infertility $(12,13)$. In our clinical practice, patients with the diagnosis of varicocele without any pathology in semen parameters are offered conservative treatments (use of analgesics or palliative treatment recommendations for pain relief) and follow up at 3-6-month intervals. We perform surgery in cases without relief of testicular pain with conservative treatment. The diagnosis of varicocele is based on physical examination without any need for additional tests. In a study by $\mathrm{WHO}$, it was demonstrated that $70 \%$ of patients were diagnosed with varicocele using venography, while in the same patients this rate was $30-40 \%$ with physical examination and physical examination had a false positive rate of $23 \%$. However, the sensitivity and specificity of physical examination in the diagnosis of varicocele were reported to be $71 \%$ and $69 \%$, respectively (14-16). We aimed to eliminate this false negativity effect by including patients with Grade 3 varicocele in our study group. Urology guidelines try to minimize this margin of error by recommending the confirmation by CDUS of the diagnosis of varicocele made by physical examination.

The benefit of additional diagnostic imaging methods usually does not go beyond supporting the diagnosis, while these methods are still used in the clinical practice of urologists. Unfortunately, the contribution of these methods in the evaluation of testicular volume and determination of venous reflux in adult patients is not substantial as in pediatric patients (17). Moreover, it contributes to the determination of surgical technique in adolescent varicocelectomy but not in adult varicocelectomy (18). We use CDUS in our practice particularly in patients with pathologies interfering with varicocele evaluation (e.g., scrotal edema, cellulitis or prior scrotal surgery), patients with recurrent varicocele and morbid obese patients. However, additional imaging methods revealed no additional result other than supporting the diagnosis and/or establishing differential diagnosis. It should be kept in mind that CDUS used in the diagnosis of varicocele is affected by many factors. Poor quality of the measuring device causes false-negative diagnoses and excessive mobility of the spermatic cord vessels leads to false-positive diagnoses (19). The employed technique is another influential factor. Measurements taken in the standing position are diagnostically more successful compared to the measurements taken in the lying or backward-leaning position (20). The caput of the epididymis is the most suitable region for optimal success of ultrasonographic measurements in varicocele evaluation (21). In analyses evaluating the success of ultrasonography, the sensitivity and specificity of color Doppler ultrasonography in the diagnosis of varicocele were $97 \%$ and $94 \%$, respectively (22). Color Doppler examination has a higher sensitivity and specificity and a lower cost compared to thermography and angiography and is a non- invasive evaluation method and the procedure of choice in the diagnosis of venous reflux in varicocele (23).

Physical examination remains the most valuable method $(24,25)$, in fact our study found no statistically significant difference between the patients who were diagnosed via physical examination and the patients whose diagnoses were supported by CDUS in terms of the numbers of internal and external spermatic veins ligated during varicocelectomy and we concluded that additional imaging had no additional predictive value compared to physical examination in the determination of the number of spermatic veins to be ligated during varicocelectomy in patients with Grade 3 varicocele. We therefore do not think that CDUS should be used as a routine method. In contrast to the failure in predicting the number of vessels ligated during varicocelectomy, there are studies in the literature reporting that there is a correlation between CDUS findings and semen parameters and/or infertility. Mahdavi et al. reported that semen volume, sperm count and sperm motility and morphology correlated with CDUS findings in patients with varicocele (26). In our study, the maximum spermatic vein diameter measured during the Valsalva maneuver by CDUS was not significantly correlated with any of the sperm parameters or the numbers of ligated external and internal spermatic veins in Group 2. Based on the results of our study, CDUS performed in addition to physical examination for the diagnosis of varicocele has no contribution to the interpretation of sperm parameters or to the prediction of the number of spermatic veins that should be ligated during the operation.

Retroperitoneal, laparoscopic, inguinal and subinguinal methods have been described for the treatment of varicocele. In recent years, studies showed that robot-assisted microscopic varicocelectomy is as successful as the conventional methods (27). However, microscopic subinguinal varicocelectomy is the golden standard for the treatment of varicocele $(28,29)$. This method includes the treatment of venous system by preserving testicular arterial and lymphatic vessels. In conventional varicocelectomy performed without using a microscope or optic magnifier, the most important cause of recurrence after the treatment of varicocele is the inability to ligate the small internal spermatic vein branches due to their invisibility to the naked eye (30). In the literature, it is reported that intraoperative indocyanine green administration is one of the ways of increasing the success of this technique and minimizing testicular artery injuries (29). Another method is the use of intraoperative microvascular Doppler ultrasonography (10). In a study evaluating 65 patients undergoing microsurgical subinguinal varicocelectomy at variance analysis, only the number of ligated veins $4 \mathrm{~mm}$ or more in diameter was higher in grade 3 varicoceles than in grade 1 and 2 varicoceles and the increase in varicocele grade was not related to the total number of ligated veins (31). In a new study, Babai et al. was reported that the presence of testicular reflux has no effect on semen analysis parameters, but also does not predict the consequences of varicocelectomy and therefore is not a suitable prognosis factor in varicocele patients (32). Also in our study, there was no statistically significant correlation between varicocele grade on physical examination or CDUS find- 
ings (diameter of the vein or presence of reflux) and the total number of ligated spermatic veins. Outcomes of this study are different from those of previous studies of Belani et al. (31) and Mahdavi et al. (26), but similar to the results of Babai et al. (32).

Based on statistical results, we have not found any radiological data that predict sperm parameters or the number of internal and external spermatic veins ligated during varicocelectomy. Therefore, it was demonstrated that inclusion of CDUS in the preoperative evaluation in patients with Grade 3 varicocele has no effect on surgical decision making or the number of ligated spermatic veins which determines the surgical success index.

The present study has several limitations. Our study is limited by the small number of patients due to a singlecenter trial. In our operations, we do not use microscopic magnification routinely during surgery and not all the patients were operated on by a single surgeon experienced in the field of andrology. The last limitation of our study was its retrospective evaluation limited to findings of patients with Grade 3 varicocele. Doppler ultrasound could be useful when varicocele is not visible or palpable. For these reasons, we believe that larger case series will be more effective in the interpretation of our study findings.

\section{Conclusions}

The best diagnostic method for grade 3 varicocele is physical examination and there is no need for additional imaging in primary cases. It is obvious that every imaging study will have an additional cost and will cause time and labor loss. Imaging studies do not contribute to surgical decision making or the prediction of surgical success. However, it should be kept in mind that physical examination is not sufficient in all cases, yet it can provide useful information particularly for the evaluation of secondary/tertiary varicocele cases and for the diagnosis of additional testicular pathologies. Despite of this, semen parameters considered in surgical decision making in patients with grade 3 varicocele do not correlate with physical examination and imaging findings, suggesting that there are more parameters that should be examined for the diagnosis and treatment of grade 3 varicocele.

\section{ACKNOWLEDGMENTS}

The authors would like to thank the entire staff of the Departments of Urology and Radiology, Sultan Abdulhamid Han Education and Research Hospital.

\section{REFERENCES}

1. Leslie SW, Sajjad H, Siref LE. Varicocele. StatPearls. Treasure Island (FL); 2019.

2. Youssef T, Abd-Elaal E, Gaballah G, et al. Varicocelectomy in men with nonobstructive azoospermia: is it beneficial? Int J Surg. 2009; 7:356-360.

3. Esteves SC, Miyaoka R, Roque M, et al. Outcome of varicocele repair in men with nonobstructive azoospermia: systematic review and meta-analysis. Asian J Androl. 2016; 18:246-253.

4. Zampieri N, Bosaro L, Costantini C, et al. Relationship between tes- ticular sperm extraction and varicocelectomy in patients with varicocele and nonobstructive azoospermia. Urology. 2013; 82:74-77.

5. Kizilay F, Altay B. Evaluation of the effects of antioxidant treatment on sperm parameters and pregnancy rates in infertile patients after varicocelectomy: a randomized controlled trial. Int J Impot Res. 2019; 31:424-431.

6. Marmar JL, Agarwal A, Prabakaran S, et al. Reassessing the value of varicocelectomy as a treatment for male subfertility with a new meta-analysis. Fertil Steril. 2007; 88:639-648.

7. Hassanin AM, Ahmed HH, Kaddah AN. A global view of the pathophysiology of varicocele. Andrology. 2018; 6:654-661.

8. Leslie SW, Siref LE. Varicocele. StatPearls. Treasure Island (FL); 2018.

9. Lomboy JR, Coward RM. The Varicocele: Clinical Presentation, Evaluation, and Surgical Management. Semin Intervent Radiol. 2016; 33:163-169.

10. Owen RC, McCormick BJ, Figler BD, et al. A review of varicocele repair for pain. Transl Androl Urol. 2017; 6:S20-S29.

11. Raghavendran M, Venugopal A, Kiran Kumar G. Thrombosed varicocele - a rare cause for acute scrotal pain: a case report. BMC Urol. 2018; 18:34.

12. Shiraishi K, Takihara H, Naito K. Testicular volume, scrotal temperature, and oxidative stress in fertile men with left varicocele. Fertil Steril. 2009; 91:1388-1391.

13. Garolla A, Torino M, Miola P, et al. Twenty-four-hour monitoring of scrotal temperature in obese men and men with a varicocele as a mirror of spermatogenic function. Hum Reprod. 2015; 30:1006-1013.

14. Gat Y, Bachar GN, Zukerman Z, et al. Physical examination may miss the diagnosis of bilateral varicocele: a comparative study of 4 diagnostic modalities. J Urol. 2004; 172:1414-1417.

15. Preutthipan S, Nicholas OA. Comparative study between scrotal physical examination and scrotal ultrasonography in the detection of varicocele in men with infertility. J Med Assoc Thai. 1995; 78:135-139.

16. Pryor JL, Howards SS. Varicocele. Urol Clin North Am. 1987; 14:499-513.

17. Macey MR, Owen RC, Ross SS, et al. Best practice in the diagnosis and treatment of varicocele in children and adolescents. Ther Adv Urol. 2018; 10:273-282.

18. Cimador M, Di Pace MR, Peritore M, et al. The role of Doppler ultrasonography in determining the proper surgical approach to the management of varicocele in children and adolescents. BJU Int. 2006; 97:1291-1297.

19. Tyloch JF, Wieczorek AP. Standards for scrotal ultrasonography. J Ultrason. 2016; 16:391-403.

20. Kim YS, Kim SK, Cho IC, et al. Efficacy of scrotal Doppler ultrasonography with the Valsalva maneuver, standing position, and resting-Valsalva ratio for varicocele diagnosis. Korean J Urol. 2015; 56:144-149.

21. Karami M, Mazdak H, Khanbabapour S, et al. Determination of the best position and site for color Doppler ultrasonographic evaluation of the testicular vein to define the clinical grades of varicocele ultrasonographically. Adv Biomed Res. 2014; 3:17.

22. Bagheri SM, Khajehasani F, Iraji H, et al. A Novel Method for Investigating the Role of Reflux Pattern in Color Doppler Ultrasound for Grading of Varicocele. Sci Rep. 2018; 8:6517. 
23. Annoni F, Colpi GM, Marincola FM, et al. Doppler examination in varicocele. A standard method of evaluation. J Androl. 1988; 9:248-252.

24. Sharlip I, Jarow J, Bekler A. AUA Best practice policy. Report on varicocele and infertility American Urological Association Inc, Baltimore, MD, USA 2001.

25. Borruto FA, Impellizzeri P, Antonuccio P, et al. Laparoscopic vs open varicocelectomy in children and adolescents: review of the recent literature and meta-analysis. J Pediatr Surg. 2010; 45:24642469.

26. Mahdavi A, Heidari R, Khezri M, et al. Can ultrasound findings be a good predictor of sperm parameters in patients with varicocele? A cross-sectional study. Nephrourol Mon. 2016; 8:e37103.

27. McCullough A, Elebyjian L, Ellen J, et al. A retrospective review of single-institution outcomes with robotic-assisted microsurgical varicocelectomy. Asian J Androl. 2018; 20:189-194.

28. Al-Kandari AM, Khudair A, Arafa A, et al. Microscopic subin- guinal varicocelectomy in 100 consecutive cases: Spermatic cord vascular anatomy, recurrence and hydrocele outcome analysis. Arab J Urol. 2018; 16:181-187.

29. Cho CL, Ho KL, Chan WK, et al. Use of indocyanine green angiography in microsurgical subinguinal varicocelectomy - lessons learned from our initial experience. Int Braz J Urol. 2017; 43:974979.

30. Cayan S, Kadioglu TC, Tefekli A, et al. Comparison of results and complications of high ligation surgery and microsurgical high inguinal varicocelectomy in the treatment of varicocele. Urology. 2000; 55:750-754.

31. Belani JS, Yan Y, Naughton CK. Does varicocele grade predict vein number and size at microsurgical subinguinal repair? Urology. 2004; 64:137-139.

32. Babai M, Gharibvand MM, Momeni M, et al. Comparison of preoperative and post-operative (varicocelectomy) sperm parameters in patients suffering varicocle with and without reflux in Doppler ultrasonography. J Family Med Prim Care. 2019; 8:1730-1734.

\section{Correspondence}

Caner Ediz, Assoc. Prof. (Corresponding Author)

drcanerediz@gmail.com

Muhammed Temel Cihan, MD

Serkan Akan, MD

Serkan Yenigürbüz, MD

Mehmet Pehlivanoğlu, $M D$

Ömer Yilmaz, MD

Department of Urology, Sultan Abdulhamid Han Education and Research Hospital Tibbiye Street. Selimiye neighborhood, 34668 Uskudar/Istanbul (Turkey)

Suna Sahin Ediz, MD

Department of Radiology, Kartal Dr. Lutfi Kirdar City Hospital, Istanbul (Turkey) 